\title{
Tissue Eosinophilia in a Mouse Model of Colitis Is Highly Dependent on TLR2 and Independent of Mast Cells
}

\author{
Eric J. Albert, ${ }^{*}$ Jon Duplisea, ${ }^{\dagger}$ Wojciech Dawicki, ${ }^{\dagger}$ \\ Ian D. Haidl, ${ }^{\dagger}$ and Jean S. Marshall ${ }^{\star \dagger}$ \\ From the Departments of Pathology* and Microbiology \& \\ Immunology, ${ }^{\dagger}$ Dalhousie University, Halifax, Nova Scotia, \\ Canada
}

The mechanisms initiating eosinophil influx into sites of inflammation have been well studied in allergic disease but are poorly understood in other settings. This study examined the roles of TLR2 and mast cells in eosinophil accumulation during a nonallergic model of eosinophilia-associated colitis. TLR2-deficient mice (TLR2 $^{-/-}$) developed a more severe colitis than wild-type mice in the dextran sodium sulfate (DSS) model. However, they had significantly fewer eosinophils in the submucosa of the cecum $(P<0.01)$ and mid-colon $(P<0.01)$ than did wild-type mice after DSS treatment. Decreased eosinophilia in TLR2 $^{-/-}$mice was associated with lower levels of cecal CCL11 $(P<0.01)$. Peritoneal eosinophils did not express TLR2 protein, but TLR2 ligand injection into the peritoneal cavity induced local eosinophil recruitment, indicating that TLR2 activation of other cell types can mediate eosinophil recruitment. After DSS treatment, mast celldeficient $\left(\mathrm{Kit}^{\mathrm{W}-\mathrm{sh} / \mathrm{W}-\mathrm{sh}}\right.$ ) mice had similar levels of intestinal tissue eosinophilia were observed as those in wild-type mice. However, mast cell-deficient mice were partially protected from DSS-induced weight loss, an effect that was reversed by mast cell reconstitution. Overall, this study indicates a critical role for indirect TLR2-dependent pathways, but not mast cells, in the generation of eosinophilia in the large intestine during experimental colitis and has important implications for the regulation of eosinophils at mucosal inflammatory sites. (Am J Patbol 2011, 178:150-160; DOI: 10.1016/j.ajpath.2010.11.041)

Crohn's disease and ulcerative colitis are characterized by chronic relapsing inflammation of the gastrointestinal tract due to inappropriate responses of the mucosal im- mune system. A cellular infiltrate composed of several cell types, including eosinophils neutrophils, monocytes, and mast cells, is associated with intestinal inflammation in these inflammatory bowel diseases (IBD). ${ }^{1-4}$ Eosinophils are multifunctional leukocytes frequently mobilized during $\mathrm{T}$ helper 2 (Th2)-driven processes, such as allergic responses and parasitic helminth infections. In these contexts, eosinophils have been implicated in the pathogenesis of disease. ${ }^{5-7}$

Eosinophil differentiation in the bone marrow and mobilization into the blood stream is regulated by a number of cytokines, including interleukin-5 (IL-5), granulocyte macrophage colony stimulating factor, and interleukin-3 (IL-3). ${ }^{8-11}$ Further recruitment into tissues during an inflammatory response is orchestrated by a number of chemoattractants, including chemokines CCL5, CCL11, CCL7, and CCL3 and leukotrienes (LTS). ${ }^{7}$ The regulation of eosinophil recruitment has been best studied in allergic diseases such as atopic asthma. The role of eosinophils in intestinal inflammation is less well studied, except in the context of parasitic nematode infestation; however, there are welldocumented intestinal inflammatory conditions in which tissue eosinophilia is a major feature, such as eosinophilic gastroenteritis and eosinophilic esophagitis. ${ }^{12,13}$ An increase in eosinophil numbers has also been reported in subsets of IBD patients. ${ }^{14,15}$ Eosinophil numbers are known to be significantly increased in the mucosa and submucosa of the colon in C57BL/6 mice after dextran sodium sulfate (DSS) treatment, a well characterized and widely used model of inducible colitis. ${ }^{16,17}$ Moreover, this eosinophil recruitment was highly dependent on the activity of CCL $11 .{ }^{16,18}$

\footnotetext{
Supported by the Crohn's and Colitis Foundation of Canada, The Atlantic Innovation Fund, and the Canadian Institutes of Health Research, by a fellowship from the Nova Scotia Health Research Foundation (E.J.A.) and by a fellowship from the Canadian Institutes of Health Research/Canadian Lung Association/GlaxoSmithKline (W.D.).

Accepted for publication September 9, 2010.

Address reprint requests to Jean S. Marshall, Ph.D., Dalhousie University, Department of Microbiology \& Immunology, Sir Charles Tupper Medical Building, Room 7C, 5850 College St., Halifax, NS B3H 1X5, Canada. E-mail: jean.marshall@dal.ca.
} 
Toll-like receptors (TLR) are a family of innate immune pattern recognition receptors that recognize pathogenassociated molecular patterns. Several TLRs are expressed in the large intestine under normal physiological conditions and during inflammation. ${ }^{19-22}$ Activation of TLRs can lead to the production of proinflammatory cytokines and chemokines involved in the recruitment of leukocytes. ${ }^{23,24}$ TLR2-deficient animals have been shown to develop more severe colitis after DSS administration than their wild-type counterparts ${ }^{25,26}$ as a result of a dysregulated interaction with intestinal microflora and altered epithelial permeability characteristics. ${ }^{27}$ Stimulation of TLR2 by Mycobacterium bovis has also been shown to induce an eosinophilic infiltration into the pleural cavity that is highly dependent on IL-5, CCL11, and CCR3 (a CCL11 receptor). ${ }^{28}$ The role of TLR2 in eosinophil recruitment during DSS colitis and the potential role of eosinophils in the severe colitis seen in TLR2 $2^{-1-}$ mice have not been previously examined.

Mast cells are strategically located at body sites that interface with the external environment, such as mucosal surfaces, where they have been shown to play an important role in host defense against parasitic and bacterial infection. ${ }^{29-34}$ Mast cells have been suggested to play a proinflammatory role in models of colitis, and there is some evidence of mast cell activation in human IBD. ${ }^{15,35,36}$ Mast cells are considered an important source of cytokines, chemokines, and other signaling factors that initiate the recruitment of eosinophils into sites of allergic inflammation. ${ }^{37-39}$ Specifically, in the gastrointestinal tract mucosal mast cells can produce significant amounts of IL-5, CCL11, and $\mathrm{LTC}_{4}$ after IgE-mediated stimulation, making them key cells to study in disease processes associated with eosinophilia. ${ }^{40}$ Mast cells also express TLR2 and can produce cytokines and lipid mediators (eg, TNF, IL-5, IL-13, $\mathrm{LTB}_{4}$, and $\mathrm{LTC}_{4}$ ) in response to TLR2 activation. ${ }^{41-43}$ The role of mast cells has not been considered in detail in the DSS model of colitis. Other reports using the $\mathrm{Kit}^{W} / \mathrm{Kit}^{\mathrm{W}-\mathrm{v}}\left(\mathrm{W} / \mathrm{W}^{\mathrm{V}}\right.$ ) mast cell-deficient mouse model suggested that their absence was not associated with changes in disease severity. Mast cell-deficient mutant $\mathrm{Kit}{ }^{\mathrm{W}-\mathrm{sh} / \mathrm{W} \text {-sh }}$ mice containing the $W$-sash $\left(W^{\text {sh }}\right)$ inversion mutation do not have many of the additional defects present in W/W ${ }^{v}$ mice. ${ }^{44}$ For example, there are normal levels of TCR $\gamma \delta$ intraepithelial lymphocytes, making $W^{\text {sh }}$ mice a much better model for studying the role of mast cells in eosinophil recruitment in the large intestine. The present study examined the role of TLR2 and mast cells in driving tissue eosinophilia during intestinal inflammation induced by DSS in mice and revealed an unexpected pivotal role for TLR2 in this process.

\section{Materials and Methods}

\section{Mice}

All mice were 8-12 weeks of age. TLR2 ${ }^{-1-}$ mice backcrossed more than 10 generations onto a C57BL/6 back- ground were kindly provided by Dr. S. Akira (Osaka University, Osaka, Japan). Mast cell-deficient B6.Cg-Kit ${ }^{W-s h} /$ HNihrJaeBsmJ mice and matched C57BL/6 control mice were obtained from Jackson Laboratory (Bar Harbor, $\mathrm{ME})$. Animals were housed under specific pathogen-free conditions and were allowed free access to regular water and food. Because our previous studies ${ }^{45}$ illustrated that cohousing of littermates will not normalize the intestinal microbiota of TLR2-deficient mice, for this study we used mice that were not co-housed from birth (except that all mice from Jackson Laboratory were housed together with other strains in the Animal Care facility at Dalhousie University for a minimum of 2 weeks before use). All experiments were conducted in accordance with the guidelines of the Canadian Council on Animal Care (local protocol no. 03-102).

\section{Mast Cell Culture and Reconstitution}

Bone marrow-derived mast cells (BMMCs) were generated from C57BL/6 mice according to the method of Tertian et al. ${ }^{46}$ The $\mathrm{W}^{\text {sh }}$ mice were reconstituted as previously described. ${ }^{47}$ Briefly, $7.5 \times 10^{6}$ mature BMMC (>98\% pure mast cells) were injected intravenously into the tail vein of 8 - to 12 -week-old $W^{\text {sh }}$ mice. Mice were allowed to mature in vivo for a minimum of 16 weeks to allow reconstitution of the gastrointestinal tract. Effective mast cell reconstitution was confirmed by histological analysis in Carnoy's-fixed, Toluidine Blue-stained paraffin sections. Mice were between 28 and 30 weeks of age when used in DSS colitis experiments.

\section{Induction of Colitis}

Mice received 3\% (w/v) DSS (mol. wt. $=36-50 \mathrm{kDa} ; \mathrm{ICN}$ Biomedicals, Aurora, $\mathrm{OH}$ ) dissolved in sterile, distilled water ad libitum on days $0-5$, followed by 5 days of regular drinking water. A similar DSS treatment protocol had been used by several groups previously. ${ }^{23,25,27}$ Mice were weighed daily. Cecal, mid-colon, and lung samples were taken for histology and tissue sonication on days 0 , 5,7 , and 10 of treatment. Peripheral blood samples were also taken from selected animals before and after treatment. This protocol yields maximal weight loss and histological damage at days 7-8 for control mice and at days $10-11$ in TLR2-deficient animals. ${ }^{26}$

\section{Histology and Sonication}

The large intestine was removed free of fatty tissue and mesenteric lymph nodes. The entire colon length was measured from the cecum to the rectum. Cecal and midcolonic portions of the large intestine were opened longitudinally, rinsed briefly in cold PBS, and further divided into two segments. One segment was frozen and saved for sonication, and the other half was fixed in 10\% neutral buffered formalin and paraffin-embedded. All samples for cytokine content analysis were placed in PBS at a constant ratio to their weights, sonicated, and centrifuged (2300 $\mathrm{g}$ for 10 minutes), with supernatants collected for cytokine assays. Paraffin-embedded tissue sections 
were cut $5 \mu \mathrm{m}$ thick and stained with hematoxylin and eosin for general histology or with Congo Red to identify eosinophils before evaluation.

\section{Congo Red Stain for Eosinophils}

Five-micron sections of paraffin-embedded, formalinfixed tissue were stained for 1 hour in $1 \%$ alcoholic Congo Red solution (1.0 g Congo Red, $50 \mathrm{ml}$ ethanol, 50 $\mathrm{ml}$ distilled water). Slides were then placed in Mayer's hematoxylin for 2 minutes, followed by a rinse with tap water. Slides were blued in Scott's tap water substitute and then rinsed again with tap water. Finally, the slides were dehydrated, cleared, and mounted. The resulting stain showed eosinophil granules as bright red and nuclei as blue.

\section{Histological Scoring and Colon Lengths}

Entire cecal and mid-colonic sections tissue sections were coded and assessed in a blinded manner. Histological damage was scored according to a previously described protocol. ${ }^{26}$ Briefly, sections were scored based on three criteria; inflammatory cell infiltration (0-3), tissue damage (0-5), and edema (0-2). For colon length measurements, the entire large intestine was removed and length was measured from the proximal end of the cecum to the anus.

\section{Eosinophil Counts}

Eosinophilia after DSS treatment was most pronounced in the submucosal area of the large intestine. In both cecal and colonic samples, the number of eosinophils in the submucosa was counted per area $\left(20,000 \mu \mathrm{m}^{2}\right)$ of submucosa in Congo Red-stained sections, based on red granule staining. Ten random fields were counted per section.

\section{Peritoneal Cavity Injections, Cell Harvesting, and Fluorescence-Activated Cell Sorting Analysis}

C57BL/6 mice were left untreated or injected with 50 $\mu \mathrm{L}$ of either saline or saline containing $1 \mu \mathrm{g}$ of a TLR2/ TLR6 agonist, FSL-1 (EMC Microcollections, Tübingen, Germany). After 16 hours, the mice were euthanized and the peritoneal cells were harvested by i.p. injection and recovery of $5 \mathrm{ml} \mathrm{PBS,} 0.5 \%$ bovine serum albu$\mathrm{min}, 5 \mathrm{mmol} / \mathrm{L}$ EDTA. The cells were counted and analyzed by fluorescence-activated cell sorting for the expression of Siglec-F, F4/80, CD11b, and Gr-1 to identify eosinophils as Siglec-F ${ }^{\text {pos }}, F 4 / 80^{\circ}, C D 11 b^{\text {lo/neg }}$, and Gr$1^{\text {neg }}$ (all antibodies from eBioscience, San Diego, CA). Cells were collected on a FACSCalibur or FACSAria system (BD Biosciences, San Jose, CA) and were analyzed with WinList version 5.0 software (Verity Software House, Topsham, $\mathrm{ME})$.

\section{Mast Cell Staining}

Five-micron sections of Carnoy's-fixed, paraffin-embedded tissue were stained for mast cells using an adaptation of the method of Strobel, Miller, and Ferguson. ${ }^{48}$ Toluidine Blue stain was dissolved in $1 \mathrm{~N} \mathrm{HCl}$ to provide better discrimination from goblet cell background tissue staining within the large intestine.

\section{White Blood Cell Counts and Differentiation}

Venous blood was collected from the aorta of mice immediately after sacrifice. Total white blood cell counts were performed on a hemocytometer after dilution of blood 1:10 in crystal violet solution. Blood smears were prepared and stained with Diff Quick stain set (Dade Behring, Newark, NJ) according to the manufacturer's protocol. Smears were examined at $\times 400$ magnification. Two hundred white blood cells were counted per smear, and differentiation of lymphocytes, monocytes, eosinophils, and neutrophils was performed based on nuclear morphology and cytoplasmic staining properties.

\section{Enzyme-Linked Immunosorbent Assays}

Enzyme-linked immunosorbent assays (ELISAs) were performed on cell-free supernatants according to the manufacturers' protocols. Detection of IL-5 was performed using a DuoSet mouse IL-5 ELISA development system (R\&D Systems, Minneapolis, MN) (sensitivity: $31.25 \mathrm{pg} / \mathrm{ml}$ ). Amplification of the IL-5 ELISA was performed using a commercial ELISA amplification system (Invitrogen, Carlsbad, CA). Eotaxin ELISA was performed on cell-free supernatants using a Quantikine Mouse eotaxin immunoassay kit (R\&D Systems) according to the manufacturer's protocol (sensitivity was $15.6 \mathrm{pg} / \mathrm{ml}$ ). In general, cytokine content results were evaluated on a per-gram wet-weight basis. Protein content assays were also performed on a substantial subset of colon and cecum tissue samples from both control and inflamed mouse intestine, and cytokine contents were also calculated using this parameter. These values were highly correlated $(P<0.001)$ with the wet weight values.

\section{Statistical Analyses}

Results are reported as Mean $+/-$ standard error of the mean (S.E.M.). Differences between TLR2 ${ }^{-/-}$and wildtype mice and between $\mathrm{W}^{\text {sh }}$ and wild-type mice at a given time point were assessed using a one-way analysis of variance with a Bonferroni multiple comparison post hoc test. Comparisons of saline-injected versus FSL-1injected mice and, where appropriate, individual groups of mice before and after DSS treatment, were performed using an unpaired $t$-test. A $P$-value of $<0.05$ was considered significant. 
A
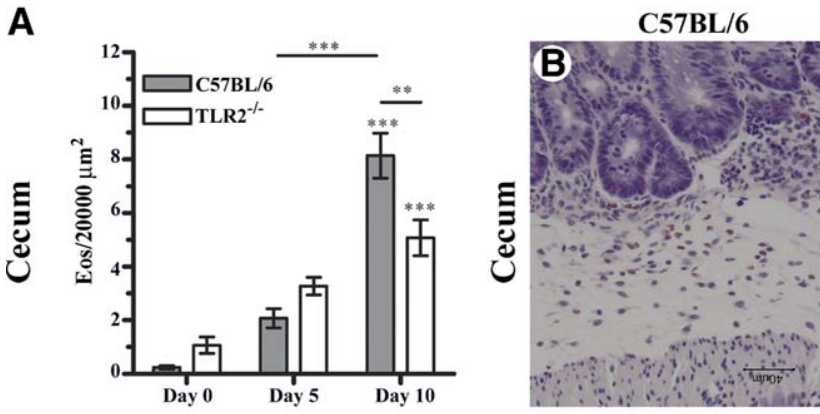

D
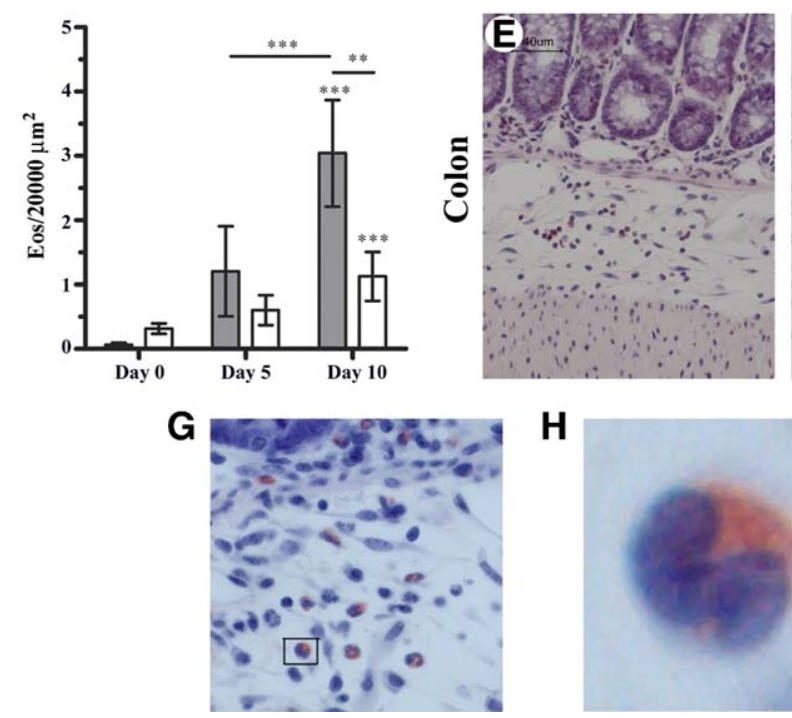

H

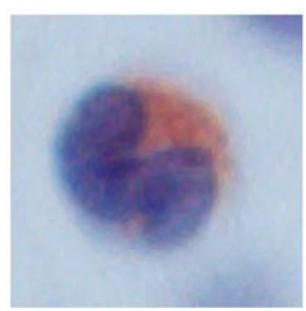

TLR2-/-
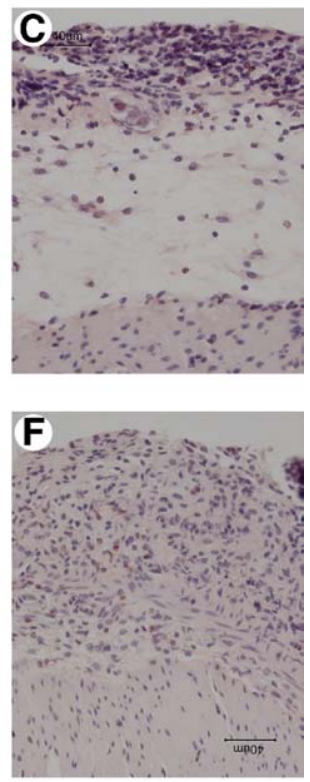

Figure 1. TLR $2^{-1-}$ mice have reduced eosinophil numbers in the large intestine after DSS treatment. TLR ${ }^{-/-}$and wild-type C57BL/ 6 mice were treated with $3 \%$ DSS (w/v) for 5 days followed by 5 days of regular drinking water. Eosinophils (Eos) were counted in the submucosa in 10 random fields of Congo Red-stained cecal (A) and mid-colonic (D) tissue sections from each mouse. Values are pooled means \pm SEM of 5-10 mice per time point from two separate experiments. Significance is denoted as ${ }^{* *} P<$ 0.01 , and ${ }^{* * *} P<0.001$. Unless indicated by a line showing a specific additional comparison, significance denotes increase compared with day 0 values for the same type of mouse. B, C: Hematoxylin and eosin stained cecal sections at $\times 400$ magnification showing the severity of disease and eosinophils in the submucosa in C57BL/6 and TLR2 ${ }^{-/-}$mice, respectively. E, F: Hematoxylin and eosin stained mid-colonic sections at $\times 400$ magnification showing the severity of disease and the presence of eosinophils in the submucosa. G: Representative Congo Red staining for eosinophils used to count eosinophils in the submucosa at $\times 1000$ magnification. H: Detail from a boxed area. G, showing eosinophil-specific Congo Red staining.

\section{Results}

\section{TLR2 Is Critical for the Generation of Eosinophilia in the Large Intestine during Colitis}

According to several reports, TLR2 ${ }^{-1-}$ mice develop more severe intestinal inflammation than wild-type mice when treated with $3 \%$ DSS $(\mathrm{w} / \mathrm{v})$ for 5 days, followed by an additional 5 days of regular water administration. ${ }^{25,26}$ We examined eosinophil recruitment in the cecums and mid-colons of TLR2 ${ }^{-/-}$and wild-type mice after DSS treatment. Under normal physiological conditions, there were comparable levels of eosinophils in both the cecum and mid-colon of $\mathrm{TLR}^{-/-}$and wild-type mice (Figure 1, A and D), and there were no significant differences between the number of peripheral blood eosinophils before treatment (data not shown). After 5 days of DSS treatment and 5 days of recovery (day 10), there was a significant increase in the number of submucosal eosinophils in the cecum of $\mathrm{TLR}^{-1-}$ and wild-type mice $(P<0.001)$ assessed by Congo Red staining (Figure 1, G and $\mathrm{H}$ ). There were, however, significantly fewer eosinophils in the submucosa of TLR2 ${ }^{-1-}$ mice, compared with wild-type mice $(P<0.01)$ (Figure 1, A-C). The same trend was also observed in the mid-colon (Figure 1, D-F), demonstrating that TLR2 plays an important role in the development of tissue eosinophilia during DSS-induced colitis.
Histologically, TLR2 ${ }^{-1-}$ mice showed more severe mucosal ulceration and inflammation in the cecum and midcolon, compared with wild-type mice, despite a relative lack of eosinophils in the submucosa (Figure 1, B, C, E, and F). Consistent with previous findings, TLR2-deficient mice showed worsened histological scores during the restitution phase of the model (for scoring, see Materials and Methods). During the induction phase, at day 5 mean colon histological scores in C57BL/6 were $4.0 \pm 0.63$ ( $n$ $=6$ ), whereas TLR2 ${ }^{-1-}$ mice had a similar mean score of $5.2 \pm 0.48(n=6)$. By day 10 , however, control C57BL/6 mice had recovered slightly, with a mean histological score of $3.6 \pm 0.49(n=11)$, whereas TLR2 ${ }^{-1-}$ mice had a significantly $(P<0.05)$ greater score of $6.3 \pm 0.91(n=$ 12).

Weight loss in these animals showed a similar pattern. At day 5 , the percent weight loss of C57BL/6 mice was $-3.0 \pm 1.03 \%(n=18)$, whereas TLR2 ${ }^{-1-}$ had lost very little weight: $-0.3 \pm 0.67 \%(n=18)$. In contrast, by day 10 the TLR2-deficient animals had very much greater weight loss than control mice who had undergone the same DSS treatment regime: $-5.3 \pm 1.54 \%$ for the C57BL/6 mice $(n=12)$ versus $-15.6 \pm 1.61 \%$ for the TLR2 ${ }^{-1-}$ mice $(n=12)$. Similar results were observed in a separate experiment using smaller groups $(n=6)$ of TLR2-deficient and control mice that had both been bred within one facility and were co-housed: weight loss for $\mathrm{C} 57 \mathrm{BI} / 6$ mice at day 10 was $-6.2 \pm 1.6 \%$, compared with 


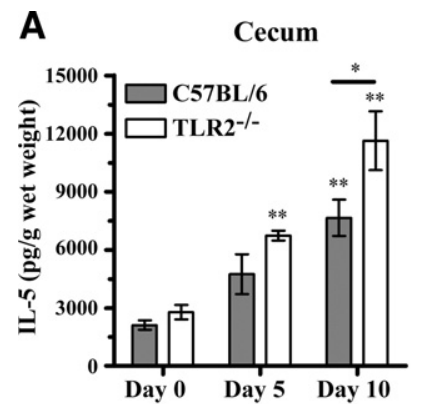

B

Colon

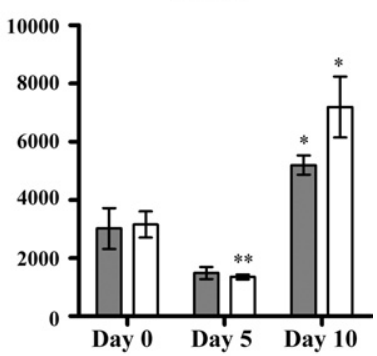

C

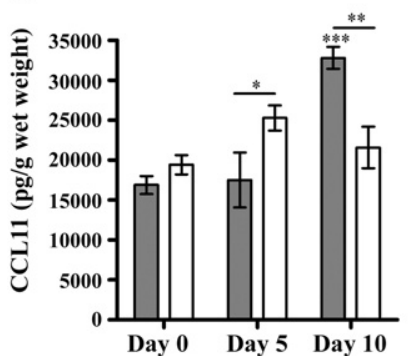

D

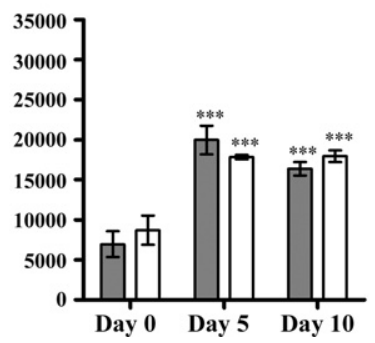

Figure 2. TLR $2^{-/-}$mice have reduced levels of eosinophil chemoattractants in the large intestine after dextran sodium sulfate (DSS) treatment. TLR2 ${ }^{-1}$ and wild-type C57BL/ 6 mice received 3\% DSS in drinking water for 5 days, followed by 5 days of regular water. Tissue samples were ultrasonicated and supernatants were assayed for total tissue interleukin-5 (IL-5) and eotaxin levels using enzyme-linked immunosorbent assay (ELISA). Values are means \pm SEM of $5-6$ mice per time point. Significance is denoted as ${ }^{*} P<$ 0.05 , ${ }^{* *} P<0.01$, and ${ }^{* * * * *} P<0.001$. Except where a specific additional comparison between groups is indicated by a line, significance in day 5 and day 10 groups shown is based on a comparison with the illustrated baseline (day 0) values from the same type of mouse.

$-14.8 \pm 2.3 \%$ for the TLR2 ${ }^{-1-}$ mice. Colon eosinophil counts at day 10 were $4.0 \pm 1.2$ for C57Bl/6 mice and $1.3 \pm 0.3$ for TLR $^{-1-}$ mice, expressed as eosinophils per $20,000 \mu \mathrm{m}^{2}$.

\section{Absence of Cecal and Mid-Colonic Eosinophils in TLR2 ${ }^{-1-}$ Mice Is Associated with Decreased CCL11 Responses}

Cecal and mid-colonic levels of IL-5 and CCL11 were measured in $\mathrm{TLR}^{-1-}$ and wild-type mice before and after DSS treatment, because of their important roles in mediating eosinophil recruitment to the gastrointestinal tract. ${ }^{16,17}$ In untreated mice, there were no significant differences between TLR2 ${ }^{-1-}$ and control mice in the levels of IL-5 or CCL11 in the cecum or the mid-colon (Figure 2). After DSS treatment, cecal and colonic CCL11 levels significantly increased in both groups of mice; however. the CCL11 response in the cecum was significantly earlier in TLR2 ${ }^{-1-}$ mice, being observed at day 5 , whereas control animals showed no increase over baseline at this time point. By day 10, however, the CCL11 response of wild-type animals was much greater than that observed in the TLR2 ${ }^{-1-}$ animals $(P<0.001)$. No differences in CCL11 levels were observed between mouse groups in the mid-colon.

\section{Mast Cell-Deficient $W^{\text {sh }}$ Mice Are Less Susceptible than Wild-Type C57BL/6 Mice to DSS-Induced Weight Loss but Show Similar Levels of Histological Damage}

Mast cells have been implicated as contributors to local inflammation during IBD because of their ability to synthesize many different mediators. ${ }^{15,35,36}$ To date, no reported studies have examined the contribution of the mast cell during DSS colitis using mast cell-deficient $K i t^{W-s h} / W$-sh $\left(W^{\text {sh }}\right)$ mice. Mast cell-deficient mice, wild-type $\mathrm{C} 57 \mathrm{BL} / 6$, and $\mathrm{W}^{\text {sh }}$ mice reconstituted intravenously with $7.5 \times 10^{6} \mathrm{C} 57 \mathrm{BL} / 6$ BMMCs were all treated with $3 \%$ DSS for 5 days, followed by 2 or 5 days of regular drinking water. During this time period, mice were weighed daily to determine the mean percent change in weight of each animal. The $\mathrm{W}^{\text {sh }}$ mice were significantly more resistant to DSS-induced weight loss than wild-type C57BL/6 mice. Compared with mast cell-deficient $W^{\text {sh }}$ mice, mast cell-containing C57BL/6 mice had lost a significantly greater percentage of weight on days $7(P<0.01)$, $8(P<0.05), 9(P<0.01)$, and $10(P<0.05)$ (Figure $3 \mathrm{~A})$. The $\mathrm{W}^{\mathrm{sh}}$ mice reconstituted with $\mathrm{C} 57 \mathrm{BL} / 6$ BMMCs showed a trend in weight loss similar to that observed in wild-type C57BL/6 mice. On histological examination, C57BL/6 and $W^{\text {sh }}$ mice had similar, significantly elevated levels of mucosal ulceration by day 7 in both the cecum and mid-colon $(P<0.01)$ (Figure 3, B and C). By day 10, however, C57BL/6 mice still had an elevated histological score in the cecum, whereas $W^{\text {sh }}$ mice had significantly less mucosal ulceration $(P<0.05)$. Mast cell-reconstituted mice showed similar responses to $W^{\text {sh }}$ mice, suggesting that this effect was not mast cell-related. Similar differences were not observed in the mid-colon.

We further examined the contribution of mast cells to the inflammatory response by measuring total cecal and mid-colonic tissue levels of the proinflammatory cytokine IL-1 $\beta$ (Figure 3, D and E). All groups of mice showed similar IL-1 $\beta$ responses in the cecum, and differences between $\mathrm{W}^{\text {sh }}$ and control mice observed at day 10 in the colon did not appear to be mast cell-related.

\section{Mast Cells Do Not Play a Significant Role in Large Intestinal Tissue Eosinophilia in DSS Colitis}

Mast cells have been shown to express TLR2, and these cells can respond to a number of TLR2 activators by producing cytokines and lipid mediators, such as TNF, IL-5, IL-13, granulocyte macrophage colony stimulating factor, and $\mathrm{LTC}_{4} \cdot{ }^{41-43}$ Mast cells are also known to mediate eosinophil recruitment during allergic disease. We were therefore interested in studying the contribution of the mast cell in the nonallergic DSS model of colitis in mice, where we have already observed significant eosinophilia in the large intestine. In untreated mast cell-deficient $W^{\text {sh }}$ mice, there were similar levels of eosinophils in 


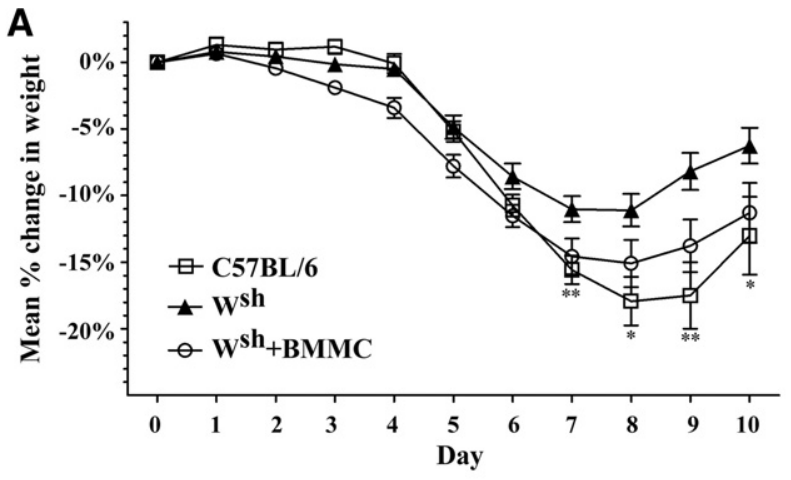

B

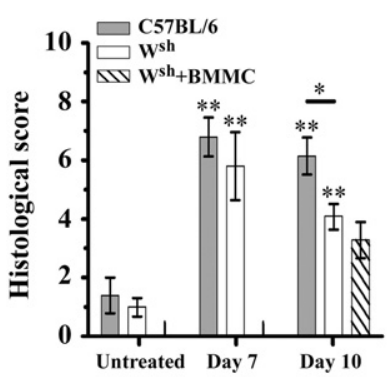

C

Colon

D

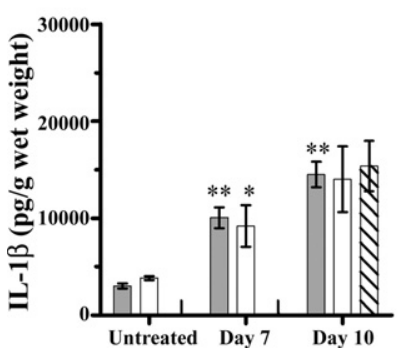

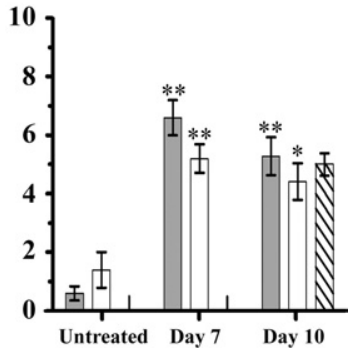

E

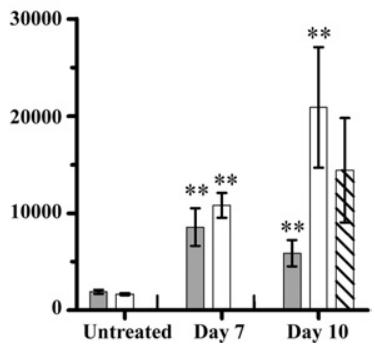

Figure 3. Mast cell-deficient mice are less susceptible to DSS-induced weight loss and colitis in the cecum. Mast cell-deficient ( $\mathrm{W}^{\text {sh }}$ ), wild-type $\mathrm{C} 57 \mathrm{BL} / 6$, and $\mathrm{W}^{\mathrm{sh}}$ mice mast reconstituted intravenously with $7.5 \times 10^{6}$ C57BL/ 6 bone marrow-derived mast cells ( $\mathrm{W}^{\mathrm{sh}}+\mathrm{BMMC}$ ) received $3 \% \mathrm{DSS}$ in drinking water for 5 days, followed by $2(n=5)$ or 5 days $(n=9-12)$ of regular water. A: Percent weight change of $\mathrm{C} 57 \mathrm{BL} / 6$ and $\mathrm{W}^{\text {sh }}$ mice. Values are means \pm SEM. B, C: Histological assessment of disease activity in H\&Estained tissue sections from the cecum $(\mathbf{B})$ and mid-colon $(\mathbf{C})$ before $(n=5)$ and after ( $n=5-12$ per group) DSS administration. Values are means \pm SEM Scoring was as described under Materials and Methods. Cecal and midcolonic tissue samples were removed and ultrasonicated, and supernatants were assayed for total tissue IL-1 $\beta(\mathbf{D}, \mathbf{E})$ levels using ELISA. Values are means \pm SEM of 5-12 mice per time point. Significance compared with baseline (day 0 ) values for each group of mice is denoted as ${ }^{*} P<0.05$ and ${ }^{\text {**a }} P<0.01$

the submucosa of the cecum and mid-colon, compared with wild-type C57BL/6 mice (Figure 4).

Cecal and mid-colonic tissue samples were taken on days 7 and 10, after mice had been administered 3\% DSS for 5 days, followed by either 2 or 5 days of regular water. Numeration of eosinophils in the submucosa of Congo Red-stained sections on day 7 demonstrated a significant number of eosinophils recruited to the cecum $(P<0.05)$ and colon $(P<0.01)$ of $\mathrm{C57BL} / 6$ mice, but this was not demonstrated to be mast cell-dependent (Figure 4). By day 10, the number of eosinophils in the submucosa of the cecum and mid-colon were still significantly elevated above baseline $(P<0.01)$ in both mast cell-

containing and mast cell-deficient animals (Figure 4). On day 7 , cecal CCL11 levels increased above baseline in both groups of mice, but by day 10 CCL11 levels decreased more rapidly in the absence of mast cells $(P<$ 0.05 ) (Figure 5C). A similar trend of elevated IL-5 and CCL11 in both groups of mice was seen in the mid-colon on day 7 , but there was no significant role for the mast cell in the regulation of IL-5 or CCL11 at this site. (Figure 5, B and D).

\section{Mast Cell Deficiency Is Associated with Altered Peripheral Blood Leukocyte Numbers before and after DSS Treatment}

We further characterized the effects of mast cell deficiency on leukocyte populations isolated from the peripheral blood of $W^{\text {sh }}$ and wild-type C57BL/6 mice before and after DSS treatment (Table 1 ). Untreated $W^{\text {sh }}$ mice had significantly fewer lymphocytes present in the peripheral circulation than did wild-type mice $(P<0.05)$. On day 7 , $W^{\text {sh }}$ mice had a significant increase in the number of circulating lymphocytes from baseline $(P<0.05)$, significantly higher than numbers observed in the blood of wild-type mice $(P<0.05)$. By day 10 , circulating levels of lymphocytes in $W^{\text {sh }}$ mice were much higher than those observed at baseline $(P<0.01)$. Peripheral blood eosinophil numbers did not change in either group of mice by day 7 , but did increase in wild-type mice by day $10(P<0.05)$, to levels significantly higher than in $W^{\text {sh }}$ mice $(P<0.05)$. Notably, TLR2-deficient mice had normal numbers of eosinophils in the peripheral blood before DSS treatment $(0.2 \pm$ $0.07 \times 10^{6} / \mathrm{ml}$ ). The numbers of peripheral blood eosinophils increased by day 10 after DSS, to $0.6 \pm 0.09 \times$ $10^{6} / \mathrm{ml}$, similar to the response observed in control
A

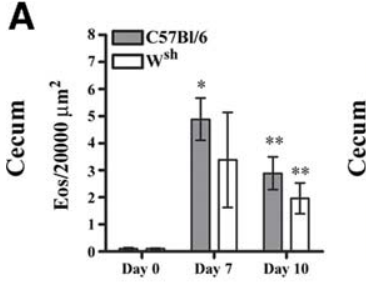

D

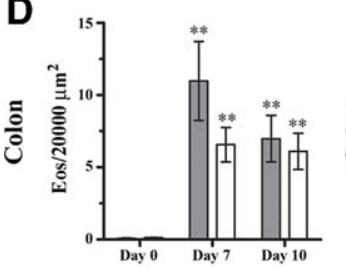

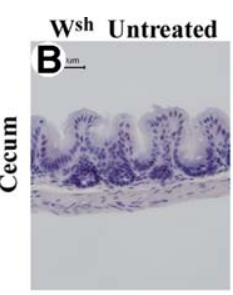

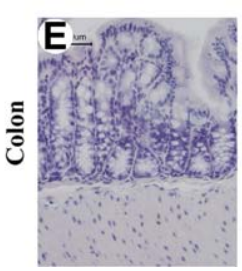

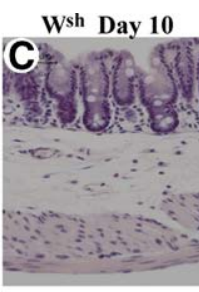

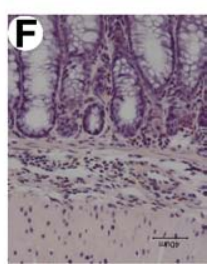

Figure 4. Mast cells do not play a significant role in eosinophil recruitment to the large intestine during DSS colitis. Mast cell-deficient $\left(\mathrm{W}^{\mathrm{sh}}\right)$ and wildtype C57BL/ 6 mice received 3\% DSS in drinking water for 5 days, followed by 2 or 5 days of regular water. Eosinophils (Eos) were counted at $\times 1000$ magnification in the submucosa of Congo Red-stained cecal (A) and midcolonic (D) tissue sections. Values are means \pm SEM of 5-12 mice per time point. Significance compared with untreated (day 0 ) animals of the same type is denoted as ${ }^{*} P<0.05$ and ${ }^{* *} P<0.01$. Representative photomicrographs ( $\times 400$ magnification) of Congo Red-stained cecal sections from untreated (B) and day $10(\mathbf{C}) \mathrm{W}^{\text {sh }}$ mice and of Congo Red-stained mid-colonic sections from untreated (E) and day $10(\mathbf{F}) \mathrm{W}^{\text {sh }}$ mice. 
A

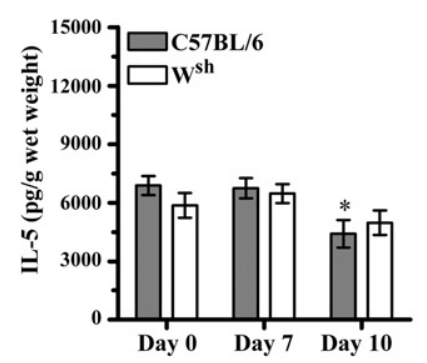

C

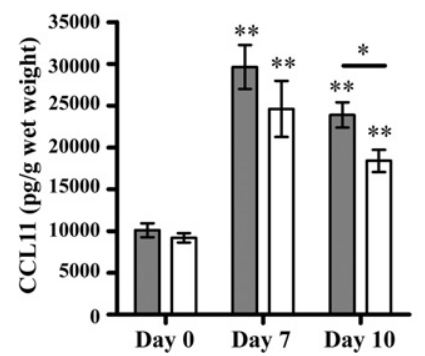

B

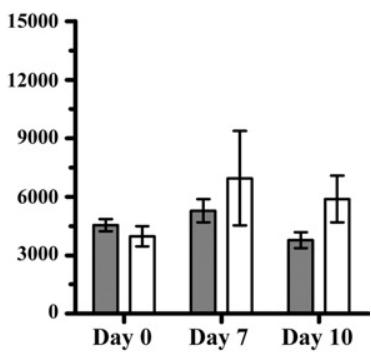

D

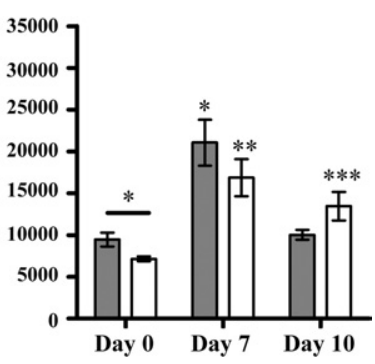

Figure 5. Mast cells do not play a role in regulating IL-5 or eotaxin levels in the large intestine during DSS colitis. Mast cell-deficient $\left(\mathrm{W}^{\mathrm{sh}}\right)$ and wild-type $\mathrm{C} 57 \mathrm{BL} / 6$ mice received 3\% DSS in drinking water for 5 days, followed by 2 or 5 days of regular water. Cecal and mid-colonic tissue samples were removed and ultrasonicated, and supernatants were assayed for total tissue IL-5 (A, B) and CCL11 (C, D) levels using ELISA. Note much larger and sustained CCL11 responses in cecal tissue than in colonic tissue. Values are means \pm SEM of 5-12 mice per time point pooled from 2 to 3 experiments per group. Except where indicated by a comparison line, significance compared with appropriate baseline (day 0 ) animals is denoted as ${ }^{*} P<0.05$, ${ }^{* * *} P<0.01$, and ${ }^{* * * *} P<0.001$

C57BL/6 DSS-treated mice at this time point ( $n=6$ per group).

\section{Resident Murine Eosinophils Do Not Express TLR2 Protein}

To assess the potential of a direct effect of TLR2 on murine eosinophil migration, we examined eosinophil expression of TLR2 using flow cytometry. Peritoneal eosinophils were identified by positive staining for Siglec- $\mathrm{F}^{49}$ in the absence of macrophage markers. Peritoneal macrophage expression of TLR2 was examined in parallel as a positive control. Peritoneal eosinophils from untreated mice exhibited no significant TLR2 staining, whereas

macrophages demonstrated substantial TLR2 expression (Figure 6A).

\section{TLR2 Activator FSL-1 Induces Peritoneal Eosinophil Recruitment}

To further examine the ability of TLR2 to mediate the recruitment of eosinophils, outside the context of a site of active inflammation and tissue damage, we injected the TLR2/TLR6 activator FSL-1 into the peritoneal cavity of C57BL/6 mice. Sixteen hours later, peritoneal cells were harvested and the number of eosinophils present was determined. An increased number of eosinophils was observed within the peritoneal cavity of FSL-1-injected animals, compared with diluent-injected controls, indicating TLR2-dependent eosinophil recruitment (Figure 6B).

\section{Discussion}

Eosinophilic inflammation is strongly associated with allergic disease and parasitic infection. However, there are a number of other inflammatory settings in which eosinophils can be a prominent feature. These include eosinophilic gastroenteritis ${ }^{12,13}$ and models of xenotransplantation ${ }^{50}$ and chitin administration. ${ }^{51}$ The mechanisms of eosinophil recruitment in allergic models are thought to include an important contribution from mast cell mediators. The role of Toll-like receptors in triggering the accumulation of eosinophils in inflamed tissues has not been widely examined. In the present study, a critical role for TLR2 was noted in the accumulation of eosinophils at inflammatory sites during DSS colitis. In contrast to allergic models, eosinophil accumulation in the DSS colitis model was found to be entirely independent of mast cells. Although murine eosinophils were not found to express TLR2, an important role for TLR2 in eosinophil recruitment was confirmed by direct administration of a synthetic TLR2/TLR6 activator (FSL-1) into the peritoneal cavity and subsequent observation of increased local eosinophil populations. The mechanism of eosinophil recruitment in the peritoneum is likely to be quite distinct from that in DSS colitis, but the present findings suggest a broader potential role for TLR2 in mediating local eosinophilia at both intestinal and alternate locations.

Eosinophils have been observed in the intestinal tissues of patients with Crohn's disease and ulcerative co-

Table 1. Total Peripheral White Blood Cell and Differential White Blood Cell Numbers

\begin{tabular}{|c|c|c|c|c|c|c|}
\hline & \multicolumn{2}{|c|}{ Day $0\left(\times 10^{-6}\right)$} & \multicolumn{2}{|c|}{ Day $7\left(\times 10^{-6}\right)$} & \multicolumn{2}{|c|}{ Day $10\left(\times 10^{-6}\right)$} \\
\hline & $\mathrm{C} 57 \mathrm{BI} / 6$ & $W^{\text {sh }}$ & C57BI/6 & $W^{\text {sh }}$ & C57BI/6 & $W^{\text {sh }}$ \\
\hline $\mathrm{WBC} / \mathrm{ml}$ & $13.1 \pm 0.9$ & $7.3 \pm 2.0$ & $7.8 \pm 0.8^{\star}$ & $11.9 \pm 0.4^{\dagger}$ & $19.4 \pm 2.7$ & $12.4 \pm 0.7$ \\
\hline PMN & $0.6 \pm 0.07$ & $0.8 \pm 0.2$ & $1.1 \pm 0.1^{*}$ & $1.8 \pm 0.4$ & $3.8 \pm 0.8^{*}$ & $1.8 \pm 0.4^{\star}$ \\
\hline Eosinophils & $0.2 \pm 0.08$ & $0.3 \pm 0.04$ & $0.2 \pm 0.05$ & $0.3 \pm 0.04$ & $0.5 \pm 0.1^{*}$ & $0.2 \pm 0.03^{\dagger}$ \\
\hline Monocytes & $0.9 \pm 0.1$ & $0.5 \pm 0.09$ & $0.2 \pm 0.05^{\star}$ & $0.3 \pm 0.01$ & $1.2 \pm 0.2$ & $0.6 \pm 0.1$ \\
\hline Lymphocytes & $9.8 \pm 0.6$ & $4.0 \pm 1.0^{\dagger}$ & $6.2 \pm 0.9$ & $9.4 \pm 0.6^{\star \dagger}$ & $13.9 \pm 2.1$ & $9.8 \pm 1.0^{*}$ \\
\hline
\end{tabular}

Total WBC were counted using crystal violet staining, and differential white blood cell counts were performed on stained blood smears. Values are expressed as mean $\times 10^{6} \pm$ SEM, $n=4-7 /$ group. PMN, polymorphonuclear leukocytes; WBC, white blood cells.

*Significant difference $(P<0.05)$ compared with untreated mice.

+Significant difference $(P<0.05)$ between $\mathrm{C} 57 \mathrm{BI} / 6$ and $\mathrm{W}^{\text {sh }}$ mice at a given time point. 
A

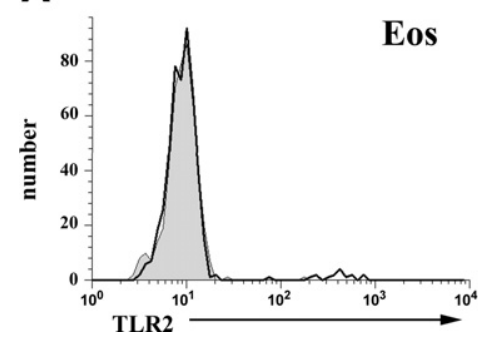

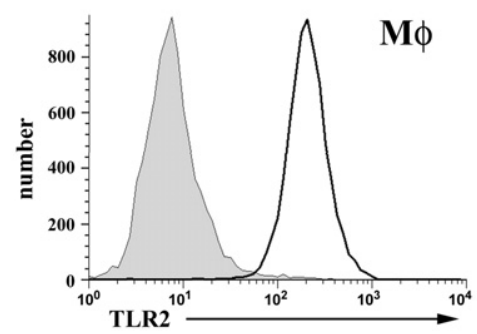

B

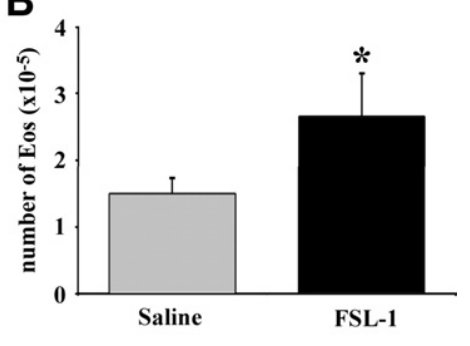

Figure 6. Eosinophils do not express TLR2, but are recruited to the peritoneum by TLR2 agonist treatment. A: Resident peritoneal cells were harvested from wild-type mice and analyzed by fluorescence-activated cell sorting (FACS) for the expression of TLR2 on eosinophils (Eos) or macrophages (M $\phi$ ). TLR2 expression is indicated by open profiles, with shading for isotype controls. Electronic gating to identify eosinophils and macrophages was based on forward and side scatter followed by selection of either Siglec-F ${ }^{+}$(Eos) or CD11b ${ }^{\text {hi }}(\mathrm{M} \phi)$ cells. B: The TLR2 agonist FSL-1 (1 $\mu \mathrm{g}$ ) or saline was injected i.p. into C57BL/ 6 mice. After 16 hours, the number of eosinophils in the peritoneum was determined based on the total number of peritoneal cells and the percentage of Siglec- $\mathrm{F}^{+}$cells observed by FACS analysis. Values are means \pm SEM of $11-12$ mice per treatment. Significance compared with the saline-treated group is denoted as ${ }^{*} P<0.05$.

litis as well as in the airways of asthmatics, but their contribution to the observed pathology of these diseases remains uncertain. ${ }^{14,52}$ Eosinophil accumulation in the mucosa is a common feature observed during DSS-induced colitis in mice. ${ }^{16,17}$ We and others have previously shown that TLR2 signaling in response to the commensal microflora is important in limiting mucosal injury during DSS colitis. ${ }^{25,26}$ TLR2-deficient animals have been shown to have a more severe disease development, with an extended time course and slower recovery after cessation of DSS treatment. ${ }^{25}$ Notably, the maximal weight loss in TLR2-deficient animals occurs at days 10-11 after a 5-day DSS treatment protocol, whereas control mice have maximal weight loss at days $7-8$. The TLR2 animals do not fully recover their weight even after 18 days, whereas control animal are largely recovered by days 12-14. ${ }^{25,26}$ A second potential explanation for worsened disease after DSS colitis is that TLR2 expression is important for maintaining epithelial barrier integrity, ${ }^{27}$ which is consistent with both the altered epithelial junction structure in TLR2-deficient mice and the high expression of TLR2 on murine intestinal epithelium. Notably, TLR2 is not expressed in substantial amounts on normal murine eosinophils.

In the present study, we demonstrated an important role for TLR2 in the regulation of CCL11 and IL-5 during experimentally induced colitis in the large intestine. After the initiation of colitis, mice deficient in TLR2 had reduced eosinophil numbers in both the cecum and the colon, coincident with significantly decreased levels of CCL11 in the cecum; however, the levels of tissue IL-5 did not show a similar pattern. Cecal IL-5 levels were significantly enhanced in TLR2-deficient at day 10, compared with C57BL/6 animals. A similar trend was observed in the colon, although this did not reach statistical significance. The levels of eosinophils in the blood of both TLR2-deficient and C57BI.6 mice were similar at that time after initiation of DSS treatment. These observations point to a predominant role of local CCL11 production in regulating local tissue eosinophil numbers with increased IL-5 production, providing an appropriate signal for the development of sufficient eosinophils in the bone marrow. Throughout the present study, chemokine and cytokine tissue levels were compared only between groups of animals that had been housed together for a substantial period of time, were fully age- and sex-matched, and from which tissues were harvested and processed for analysis in parallel. Comparison of major animal groups at day 0 or day 10 using either protein content or wet weight as a denominator for cytokine values led to similar findings; therefore, only wet weight values were reported.

In this nonallergic model of eosinophilia we found no significant role for mast cells in modulating eosinophil accumulation in the large intestine and no substantial differences between mast cell-containing and mast celldeficient mice in IL-5 or CCL11 responses. Mast cells in the lamina propria and submucosa have been implicated as contributors to local inflammation during IBD because of their ability to synthesize mediators such as histamine, prostaglandins, leukotrienes, cytokines, chemokines, and proteases. ${ }^{15,35,36}$ The $\mathrm{W}^{\text {sh }}$ mice were found to be more resistant to DSS-induced weight loss and mucosal damage in the cecum than C57BL/6 mice, a process that was confirmed to be mast cell-dependent by reconstitution studies. Mast cells have been shown by a number of groups to modify the epithelial barrier function within the intestine and, when activated, to increase intestinal permeability and fluid loss. ${ }^{53-57}$ Such processes could explain enhanced weight loss in mast cell-containing animals.

The observed reduced levels of CCL11 in the absence of TLR2 and the association with decreased levels of submucosal eosinophils are consistent with other studies that have identified IL-5 and CCL11 as major contributors to the recruitment of eosinophils in experimental models of colitis in mice. ${ }^{16,17}$ Mediators such as CCL5, $\mathrm{LTB}_{4}$, and $\mathrm{LTC}_{4}$ have also been implicated in models of local eosinophilic inflammation and may have a role in the eosinophilic response noted in DSS colitis. ${ }^{7}$ In other models of pathogen-induced eosinophilia, it has been shown that direct stimulation of TLR2 by $M$. bovis can induce an eosinophilic infiltration into the pleural cavity that is highly dependent on IL-5, CCL11, and the CCL11 receptor CCR3. ${ }^{28}$ Our results suggest that TLR2-mediated eosinophil recruitment also occurs in the gastrointestinal tract, potentially as a result of exposure of effector cells to products of the bacterial flora.

The role of eosinophils in the pathogenesis of ulcerative colitis is controversial. However, Forbes et al ${ }^{16} \mathrm{dem}-$ onstrated, in the DSS colitis model, that CCL11-deficient mice exhibited significantly attenuated colitis associated 
with a $45 \%$ reduction in the number of infiltrating eosinophils and a more than $70 \%$ reduction in colonic eosinophil peroxidase activity. In contrast with the CCL11-deficient animals, animals deficient in IL-5 did not show reduced disease or substantially reduced eosinophilia. These authors also demonstrated a key role for eosinophil peroxidase in enhancing tissue damage and inflammation. In their experiments, differences between control and CCL11-deficient mice were not noted during the colonic injury phase of the disease (up to day 5) but rather during later (recovery phase) time points (day 8). ${ }^{16}$ Ahrens et al ${ }^{18}$ also demonstrated reduced eosinophilia and tissue damage in DSS colitis in the absence of CCL11 and correlated eosinophil degranulation with disease severity in pediatric ulcerative colitis.

Our observations of worsened disease in TLR2-deficient animals, which have reduced numbers of eosinophils, demonstrate that eosinophil-independent mechanisms may be important in dictating the severity of disease under some circumstances, such as when there is reduced epithelial barrier function. ${ }^{27}$ In the present study, the observation that C57BL/6 mice had increased submucosal eosinophil accumulation, but less severe colitis, compared with TLR2-deficient mice, suggests that eosinophils might not be critical for driving the inflammatory process that leads to intestinal damage in TLR2deficient animals. Previous studies of cellular and cytokine responses in DSS colitis have not consistently distinguished between different areas of large intestine. Notably, in the present study the major changes in eosinophil populations were evident in both cecal and midcolonic sites; however, the scale of IL-5 and CCL11 responses differed substantially with location.

The ability of mast cells to recruit and activate eosinophils in the context of asthma and allergic disease has been well documented. ${ }^{37,40,58}$ The DSS model of colitis is a nonallergic model in which eosinophilia is commonly noted, but there are no studies examining the role of mast cells in eosinophil accumulation in this setting. Our results demonstrate that, when colitis is induced, eosinophil accumulation to the submucosa of the cecum and midcolon occurs independently of mast cells (Figure 4). In agreement with our findings, Ahrens et $\mathrm{al}^{18}$ identified intestinal macrophages as the primary producers of CCL11 after DSS treatment. This suggests that mast cellindependent mechanisms of eosinophil accumulation predominate during experimentally induced colitis. Decreased lymphocyte numbers in the peripheral blood of $W^{\text {sh }}$ mice has not been previously reported, but could influence the interpretation of studies examining T-cell and B-cell responses in such mice. Grimbaldeston et al ${ }^{44}$ conducted a thorough investigation of other defects associated with the specific c-kit mutation in mast celldeficient $K i t^{W-s h / W-s h}$ mice, but did not note any differences in peripheral blood levels of leukocyte or lymphocyte populations.

The present study clearly demonstrates a previously unrecognized role for TLR2 in regulating eosinophilic responses in a model of intestinal inflammation. The implications of this finding have yet to be examined in human $\mathrm{IBD}$, but could help provide some insight into the mech- anisms of TLR-mediated eosinophil recruitment during human disease. TLR2 polymorphisms and TLR2 function have been implicated in the development of allergic disease, ${ }^{59-61}$ and the contribution of TLR2 to the regulation of eosinophilic responses could contribute to this process. Notably, mast cells were not found to contribute substantially to the regulation of eosinophils in DSS colitis, although they have been shown to be pivotal for eosinophilic responses in models of allergic disease. Studies using airway administration of chitin demonstrated lung eosinophilic inflammation that was independent of both TLRs and mast cells, but highly dependent on $\mathrm{LTB}_{4}{ }^{51}$ Taken together with the present data, these findings suggest the existence of multiple distinct pathways whereby local tissue eosinophilia can be induced. It is likely that distinct pharmacological approaches may be required to modulate these processes therapeutically. The importance of TLR2 activation as a contributing factor to eosinophilic disease independent of mast cell activation requires further study.

\section{Acknowledgments}

The authors thank Yi-Song Wei and Nong $\mathrm{Xu}$ for their excellent technical assistance and Dr. Shizuo Akira for providing the TLR2 ${ }^{-1-}$ mice required for this study.

\section{References}

1. Xavier RJ, Podolsky DK: Unravelling the pathogenesis of inflammatory bowel disease. Nature 2007, 448:427-434

2. Rothenberg ME, Mishra A, Brandt EB, Hogan SP: Gastrointestinal eosinophils. Immunol Rev 2001, 179:139-155

3. King T, Biddle W, Bhatia P, Moore J, Miner PB Jr: Colonic mucosal mast cell distribution at line of demarcation of active ulcerative colitis. Dig Dis Sci 1992, 37:490-495

4. Nishida Y, Murase K, Isomoto H, Furusu H, Mizuta Y, Riddell RH, Kohno S: Different distribution of mast cells and macrophages in colonic mucosa of patients with collagenous colitis and inflammatory bowel disease. Hepatogastroenterology 2002, 49:678-682

5. Weller PF: Eosinophils: structure and functions. Curr Opin Immunol 1994, 6:85-90

6. Gleich GJ, Loegering DA: Immunobiology of eosinophils. Annu Rev Immunol 1984, 2:429-459

7. Rothenberg ME, Hogan SP: The eosinophil. Annu Rev Immunol 2006, 24:147-174

8. Lopez AF, Sanderson CJ, Gamble JR, Campbell HD, Young IG, Vadas MA: Recombinant human interleukin 5 is a selective activator of human eosinophil function. J Exp Med 1988, 167:219-224

9. Collins PD, Marleau S, Griffiths-Johnson DA, Jose PJ, Williams TJ: Cooperation between interleukin-5 and the chemokine eotaxin to induce eosinophil accumulation in vivo. J Exp Med 1995, 182:11691174

10. Dent LA, Strath M, Mellor AL, Sanderson CJ: Eosinophilia in transgenic mice expressing interleukin 5. J Exp Med 1990, 172:1425-1431

11. Rothenberg ME, Pomerantz JL, Owen WF Jr, Avraham S, Soberman RJ, Austen KF, Stevens RL: Characterization of a human eosinophil proteoglycan, and augmentation of its biosynthesis and size by interleukin 3, interleukin 5, and granulocyte/macrophage colony stimulating factor. J Biol Chem 1988, 263:13901-13908

12. Koga M, Fujiwara M, Hotta N, Matsubara T, Suzuki E, Furukawa S: MBP deposition in eosinophilic gastroenteritis. Allergy 2000, 55:985986

13. Bischoff SC, Mayer J, Nguyen QT, Stolte M, Manns MP: Immunnohistological assessment of intestinal eosinophil activation in patients with eosinophilic gastroenteritis and inflammatory bowel disease Am J Gastroenterol 1999, 94:3521-3529 
14. Carvalho AT, Elia CC, de Souza HS, Elias PR, Pontes EL, Lukashok HP, de Freitas FC, Lapa e Silva JR: Immunohistochemical study of intestinal eosinophils in inflammatory bowel disease. J Clin Gastroenterol 2003, 36:120-125

15. Bischoff SC, Wedemeyer J, Herrmann A, Meier PN, Trautwein C, Cetin Y, Maschek H, Stolte M, Gebel M, Manns MP: Quantitative assessment of intestinal eosinophils and mast cells in inflammatory bowel disease. Histopathology 1996, 28:1-13

16. Forbes E, Murase T, Yang M, Matthaei KI, Lee JJ, Lee NA, Foster PS, Hogan SP: Immunopathogenesis of experimental ulcerative colitis is mediated by eosinophil peroxidase. J Immunol 2004, 172:5664-5675

17. Stevceva L, Pavli P. Husband A, Matthaei KI, Young IG, Doe WF: Eosinophilia is attenuated in experimental colitis induced in IL-5 deficient mice. Genes Immun 2000, 1:213-218

18. Ahrens R, Waddell A, Seidu L, Blanchard C, Carey R, Forbes E, Lampinen M, Wilson T, Cohen E, Stringer K, Ballard E, Munitz A, Xu H, Lee N, Lee JJ, Rothenberg ME, Denson L, Hogan SP: Intestinal macrophage/epithelial cell-derived CCL11/eotaxin-1 mediates eosinophil recruitment and function in pediatric ulcerative colitis. J Immunol 2008, 181:7390-7399

19. Szebeni B, Veres G, Dezsofi A, Rusai K, Vannay A, Mraz M, Majorova E, Arató A: Increased expression of Toll-like receptor (TLR) 2 and TLR4 in the colonic mucosa of children with inflammatory bowel disease. Clin Exp Immunol 2008, 151:34-41

20. Hart AL, AL-Hassi HO, Rigby RJ, Bell SJ, Emmanuel AV, Knight SC, Kamm MA, Stagg AJ: Characteristics of intestinal dendritic cells in inflammatory bowel diseases. Gastroenterology 2005, 129:50-65

21. Cario E, Rosenberg IM, Brandwein SL, Beck PL, Reinecker HC Podolsky DK: Lipopolysaccharide activates distinct signaling pathways in intestinal epithelial cell lines expressing Toll-like receptors. J Immunol 2000, 164:966-972

22. Abreu MT, Fukata M, Arditi M: TLR signaling in the gut in health and disease. J Immunol 2005, 174:4453-4460

23. Fukata M, Michelsen KS, Eri R, Thomas LS, Hu B, Lukasek K, Nast CC, Lechago J, Xu R, Naiki Y, Soliman A, Arditi M, Abreu MT: Toll-like receptor-4 is required for intestinal response to epithelial injury and limiting bacterial translocation in a murine model of acute colitis. Am J Physiol Gastrointest Liver Physiol 2005, 288:G1055-G1065

24. Rhee SH, Keates AC, Moyer MP, Pothoulakis C: MEK is a key modulator for TLR5-induced interleukin-8 and MIP3alpha gene expression in non-transformed human colonic epithelial cells. J Biol Chem 2004, 279:25179-25188

25. Rakoff-Nahoum S, Paglino J, Eslami-Varzaneh F, Edberg S, Medzhitov R: Recognition of commensal microflora by toll-like receptors is required for intestinal homeostasis. Cell 2004, 118:229-241

26. Albert EJ, Marshall JS: Aging in the absence of TLR2 is associated with reduced IFN-gamma responses in the large intestine and increased severity of induced colitis. J Leukoc Biol 2008, 83:833-842

27. Cario E, Gerken G, Podolsky DK: Toll-like receptor 2 controls mucosal inflammation by regulating epithelial barrier function. Gastroenterology 2007, 132:1359-1374

28. D'Avila H, Almeida PE, Roque NR, Castro-Faria-Neto HC, Bozza PT: Toll-like receptor-2-mediated C-C chemokine receptor 3 and eotaxindriven eosinophil influx induced by Mycobacterium bovis BCG pleurisy. Infect Immun 2007, 75:1507-1511

29. Barrett KE, Metcalfe DD: The mucosal mast cell and its role in gastrointestinal allergic diseases. Clin Rev Allergy 1984, 2:39-53

30. Malaviya R, Ikeda T, Ross E, Abraham SN: Mast cell modulation of neutrophil influx and bacterial clearance at sites of infection through TNF-alpha. Nature 1996, 381:77-80

31. Woodbury RG, Miller HR, Huntley JF, Newlands GF, Palliser AC, Wakelin D: Mucosal mast cells are functionally active during spontaneous expulsion of intestinal nematode infections in rat. Nature 1984, 312:450-452

32. Wei OL, Hilliard A, Kalman D, Sherman M: Mast cells limit systemic bacterial dissemination but not colitis in response to Citrobacter rodentium. Infect Immun 2005, 73:1978-1985

33. Supajatura V, Ushio H, Nakao A, Okumura K, Ra C, Ogawa H Protective roles of mast cells against enterobacterial infection are mediated by Toll-like receptor 4. J Immunol 2001, 167:2250-2256

34. McDermott JR, Bartram RE, Knight PA, Miller HR, Garrod DR, Grencis RK: Mast cells disrupt epithelial barrier function during enteric nematode infection. Proc Natl Acad Sci USA 2003, 100:7761-7766
35. Fox CC, Lazenby AJ, Moore WC, Yardley JH, Bayless TM, Lichtenstein LM: Enhancement of human intestinal mast cell mediator release in active ulcerative colitis. Gastroenterology 1990, 99:119-124

36. Nolte $\mathrm{H}$, Spjeldnaes $\mathrm{N}$, Kruse A, Windelborg B: Histamine release from gut mast cells from patients with inflammatory bowel diseases. Gut 1990, 31:791-794

37. Bischoff SC: Role of mast cells in allergic and non-allergic immune responses: comparison of human and murine data. Nat Rev Immunol 2007, 7:93-104

38. Bischoff S, Crowe SE: Gastrointestinal food allergy: new insights into pathophysiology and clinical perspectives. Gastroenterology 2005 128:1089-1113

39. Theoharides TC, Kempuraj D, Tagen M, Conti P, Kalogeromitros D: Differential release of mast cell mediators and the pathogenesis of inflammation [Erratum appeared in Immunol Rev 2007:219:204]. Immunol Rev 2007, 217:65-78

40. Lorentz A, Schwengberg S, Mierke C, Manns MP, Bischoff SC: Human intestinal mast cells produce IL-5 in vitro upon IgE receptor cross-linking and in vivo in the course of intestinal inflammatory disease. Eur J Immunol 1999, 29:1496-1503

41. Supajatura V, Ushio H, Nakao A, Akira S, Okumura K, Ra C, Ogawa $\mathrm{H}$ : Differential responses of mast cell Toll-like receptors 2 and 4 in allergy and innate immunity. J Clin Invest 2002, 109:1351-1359

42. McCurdy JD, Olynych TJ, Maher LH, Marshall JS: Cutting edge: distinct Toll-like receptor 2 activators selectively induce different classes of mediator production from human mast cells. J Immunol 2003, 170:1625-1629

43. Olynych TJ, Jakeman DL, Marshall JS: Fungal zymosan induces leukotriene production by human mast cells through a dectin-1-dependent mechanism. J Allergy Clin Immunol 2006, 118:837-843

44. Grimbaldeston MA, Chen CC, Piliponsky AM, Tsai M, Tam SY, Gall

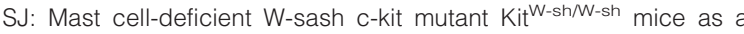
model for investigating mast cell biology in vivo. Am J Pathol 2005, 167:835-848

45. Albert EJ, Sommerfeld K, Gophna S, Marshall JS, Gophna U: The gut microbiota of toll-like receptor 2-deficient mice exhibits lineage-specific modifications. Environ Microbiol Rep 2009, 1:65-70

46. Tertian G, Yung YP, Guy-Grand D, Moore MA: Long-term in vitro culture of murine mast cells. I. Description of a growth factor-dependent culture technique. J Immunol 1981, 127:788-794

47. Nakano T, Sonoda T, Hayashi C, Yamatodani A, Kanayama $Y$ Yamamura T, Asai H, Yonezawa T, Kitamura Y, Galli SJ: Fate of bone marrow-derived cultured mast cells after intracutaneous, intraperitoneal, and intravenous transfer into genetically mast cell-deficient W/Wv mice. Evidence that cultured mast cells can give rise to both connective tissue type and mucosal mast cells. J Exp Med 1985, 162:1025-1043

48. Strobel S, Miller HR, Ferguson A: Human intestinal mucosal mast cells: evaluation of fixation and staining techniques. J Clin Pathol $1981,34: 851-858$

49. Zhang JQ, Biedermann B, Nitschke L, Crocker PR: The murine inhibitory receptor mSiglec-E is expressed broadly on cells of the innate immune system whereas mSiglec-F is restricted to eosinophils. Eur J Immunol 2004, 34:1175-1184

50. Tanaka K, Yamagami S, Streilein JW: Evidence that T-helper type 2 cell-derived cytokines and eosinophils contribute to acute rejection of orthotopic corneal xenografts in mice. Transplantation 2005, 79: $1317-1323$

51. Reese TA, Liang HE, Tager AM, Luster AD, Van Rooijen N, Voehringer D, Locksley RM: Chitin induces accumulation in tissue of innate immune cells associated with allergy. Nature 2007, 447:92-96

52. Jeziorska M, Haboubi N, Schofield P, Woolley DE: Distribution and activation of eosinophils in inflammatory bowel disease using an improved immunohistochemical technique. J Pathol 2001, 194:484492

53. Jacob C, Yang PC, Darmoul D, Amadesi S, Saito T, Cottrell GS Coelho AM, Singh P, Grady EF, Perdue M, Bunnett NW: Mast cell tryptase controls paracellular permeability of the intestine. Role of protease-activated receptor 2 and beta-arrestins. J Biol Chem 2005 , 280:31936-31948

54. Perdue MH, Ramage JK, Burget D, Marshall J, Masson S: Intestina mucosal injury is associated with mast cell activation and leukotriene generation during Nippostrongylus-induced inflammation in the rat. Dig Dis Sci 1989, 34:724-731 
55. Yu LC, Perdue MH: Role of mast cells in intestinal mucosal function: studies in models of hypersensitivity and stress. Immunol Rev 2001, 179:61-73

56. Berin MC, Kiliaan AJ, Yang PC, Groot JA, Kitamura Y, Perdue MH: The influence of mast cells on pathways of transepithelial antigen transport in rat intestine. J Immunol 1998, 161:2561-2566

57. Crowe SE, Luthra GK, Perdue MH: Mast cell mediated ion transport in intestine from patients with and without inflammatory bowel disease. Gut 1997, 41:785-792

58. Yu M, Tsai M, Tam SY, Jones C, Zehnder J, Galli SJ: Mast cells can promote the development of multiple features of chronic asthma in mice. J Clin Invest 2006, 116:1633-1641
59. Mrabet-Dahbi S, Dalpke AH, Niebuhr M, Frey M, Draing C, Brand S, Heeg K, Werfel T, Renz H: The Toll-like receptor 2 R753Q mutation modifies cytokine production and Toll-like receptor expression in atopic dermatitis. J Allergy Clin Immunol 2008, 121:1013-1019

60. Ahmad-Nejad P, Mrabet-Dahbi S, Breuer K, Klotz M, Werfel T, Herz U, Heeg K, Neumaier M, Renz H: The toll-like receptor 2 R753Q polymorphism defines a subgroup of patients with atopic dermatitis having severe phenotype. J Allergy Clin Immunol 2004, 113:565-567

61. Eder W, Klimecki W, Yu L, von Mutius E, Riedler J, Braun-Fahrländer C, Nowak D, Martinez FD; ALEX Study Team: Toll-like receptor 2 as a major gene for asthma in children of European farmers. J Allergy Clin Immunol 2004, 113:482-488 